\title{
Configuración y tiempo del antihéroe ${ }^{1}$
}

\author{
Giancarlo Cappello (Universidad de Lima, Perú) \\ Recibido 10/8/2007 \\ Aprobado 23/8/2007
}

\begin{abstract}
RESUMEN: Si la figura del héroe ha estado asociada tradicionalmente a un pasado mejor; si es el ideal paradigmático que sirve de inspiración para el futuro; si su imagen circula como una estampa de dicha que construimos e interiorizamos a través de distintos relatos para encomendarnos a sus virtudes: ¿qué ha pasado con el héroe de esta modernidad? Este texto pretende indagar en el tiempo y las características de esos personajes de la modernidad sindicados como no heroicos, pero que han ganado en aprecio y hoy lucen los mismos galones de los más famosos.
\end{abstract}

Palabras clave: Modernidad - posmodernidad - héroe/ antihéroe - narración desencanto.

\section{Antihero configuration and time}

SUMMARY: If the hero figure has been traditionally associated with better times, a time that won't come back; if he's the pragmatic ideal that inspires the future, he must be imitated, he must be reached; if the hero belongs to the victors stance; if men and arts sublime and put him in comfortable glory; if his image goes around as a figure of joy that we build and internalize through a variety of stories in which we devote ourselves to his virtues: ¿What have happened with this modernity hero? This text attempts to investigate the time and characteristics of these characters of modernity that are classified as nonheroic, but nevertheless have won our regard and today wear the same golden band of the famous.

Key words: Modernity - postmodernity - hero / antihero - narrationdisenchantment.

1 Este texto amplía algunas ideas de la ponencia "Los hombres pequeños de la modernidad", presentada en el I Coloquio de Literatura Hispanoamericana, organizado por la Escuela de Posgrado de la Pontificia Universidad Católica del Perú en abril del 2007. 
Hemos conquistado la realidad y perdido el sueño.

Ya nadie se tiende bajo un árbol a contemplar el cielo a través de los dedos del pie.

ROBERT MUSIL. El hombre sin atributos.

\section{C} ada periodo de la historia ha dado origen a un héroe específico, a un hombre elevado, distinto, capaz de reunir las cualidades más excelsas y las virtudes más apreciadas de su época. Desde la leyenda hasta los medios masivos, estos seres especiales han dejado su estela como un vestigio de tiempos memorables. Pero junto con ellos también anduvieron los otros, los hombres pequeños, los distintos y distantes de su era, los personajes de segunda línea: los antihéroes. Este texto pretende indagar en el tiempo y las características de esos personajes de la modernidad sindicados como no heroicos, pero que han ganado en aprecio y hoy lucen los mismos galones de los más famosos.

De acuerdo con las narraciones clásicas, o de régimen narrativo fuerte, según Mieke Bal, héroe es, en general, función y cualidad del personaje; es decir, el protagonista elevado que lleva la acción de la historia, pero también es el ejecutor de las funciones signadas como heroicas. La confusión surge cuando se presenta el término antihéroe, que si bien se asocia con la figura del antagonista (el villano, quien se opone a lo pactado como heroico), también designa al personaje que cumple la función heroica protagonista, aun cuando difiera en apariencia y valores.

Esta segunda acepción es la que nos interesa, y para zanjar cualquier confusión diremos que la diferencia fundamental entre ambos radica en su impostación ante la vida. El héroe no tiene fisuras ni contradicciones con respecto al espíritu que encarna. El antihéroe, en cambio, se basa en la contradicción; es, por encima de todo, un hombre, con sus defectos y sus virtudes. El héroe, en cualquiera de sus manifestaciones, está muy lejos del hombre común porque encarna la metafísica de su tiempo, su ideología, sus valores, los ideales de una era. El antihéroe se desmarca de esta impronta al presentarse como un hombre de a pie, disfuncional con su época, diminuto en sus aspiraciones, o si acaso tiene pretensiones de grandeza, inoperante, negado para alcanzar la meta de sus proyectos, porque pertenece a una casta distinta, y si la alcanza, es incapaz de conseguir para sí los réditos que toda empresa exitosa genera. En esta línea, el antihéroe moderno es hijo espurio de la Ilustración y la Revolución Francesa, las mismas que modelaron al héroe bajo las consignas de libertad, igualdad y fraternidad, iluminadas por la razón y con las miras bien puestas en el futuro.

Si la idea de modernidad es definida por la destrucción de los órdenes antiguos y por el triunfo de la raciona- 
lidad, objetiva e instrumental, se entenderá que el héroe moderno no necesite de la habilidad física para imponerse. Su mejor disparo es el argumento y su arma favorita el ingenio multiforme, mecánico e industrioso. Nos gustan los personajes de Verne para ilustrar este arquetipo: amos de la técnica, la ciencia y el saber, sacerdotes del pragmatismo y científicos de una vida desprovista de misterio, capitanes de todos los excesos que estas empresas suponen y alientan en favor de unos ideales superiores que tienen al hombre como pieza más importante.

Sin embargo, en el seno de este mismo vértigo aparecen también los seres de la paradoja, los convidados de piedra, distintos de la matriz originaria y arquetípica. En el caso del antihéroe moderno, sus fisuras de conducta, su pérdida de ejemplaridad moral, su ausencia de vocación colectiva y su incapacidad para asimilarse al curso de la historia que le toca vivir, lo desmarcan definitivamente de cualquier heroísmo. "Athos, un borracho; Porthos, un idiota; Aramis, un hipócrita conspirador...", dice el personaje de Liana Taillefer en El Club Dumas, de Arturo Pérez-Reverte, y su diagnóstico parece certero. Todo ha sido un tránsito lento pero seguro de lo divino a lo mundano.
Desde el héroe épico, en todas sus variaciones y con todo lo que implica ser la encarnación de unos ideales colectivos, pasando por el héroe del romanticismo, cuyo papel tiene que ver más con una actitud individual y de proceso personal, hasta el personaje realista de la segunda mitad del XIX, cargado de valores positivos y porfiando por dar cuenta de una sociedad que debe cambiar para mejor, en forma de pícaro, de caballero andante, de pirata o de científico alucinado, cada héroe ha sido la síntesis y el representante mayor del espíritu y los valores de su época. Los antihéroes, en cambio, han sido las Mafaldas de su tiempo, los encargados de hacer evidente el daño colateral.

En algún punto la modernidad se desbordó a sí misma, entró en crisis, y empezaron a concebirse personajes distantes del modelo que proponía. Como señala Janet Wolf: "Las narraciones de la modernidad describen la experiencia humana. Es una reacción a las complejidades de una existencia social que ha gastado sus premisas originales". ${ }^{2}$ Los protagonistas de hoy no intentan salvar el mundo porque los villanos ya no quieren conquistarlo, pues ha perdido toda gracia, está demasiado enrevesado; tampoco intentan repararlo, no buscan la gloria, quieren, sencillamente, sobrevivir. Es el tiempo del antihéroe.

2 WOLF, Janet. La producción social del arte, 1997, p. 117. 


\section{Desencanto irónico y escepticismo tragicómico}

La crisis moderna es compleja y tiene muchas aristas; sin embargo, el aspecto que nos interesa reseñar es aquel referido al sujeto, una crisis que según Jameson empezaría a fines de la década de 1950, cuando la consolidación del capitalismo coincide con la contabilidad de los últimos estragos causados por la aplicación fanática de los ideales modernos sobre el Estado-nación a manos de los nazis. ${ }^{3}$ Es decir, cuando se hace evidente que el tren que viene de la felicidad trayendo el cambio histórico, nunca llegará; cuando el sueño de progreso de Prometeo se transforma en la pesadilla de Sísifo, de que todo es inútil. Solo así se entiende que desencanto, decadentismo, nihilismo y otras etiquetas afines se hayan instalado como diagnóstico de un tiempo vacío, desprovisto de trascendencia y metafísica.

Si Marx había propuesto dejar de interpretar el mundo para transformarlo, ahora se constata que tampoco eso es posible. Y si a Marx Prometeo le parecía el mayor santo de la historia, sus nietos podrían argumentar hoy que en verdad fue un tremendo papanatas que acabó con las entrañas devoradas por una causa sin sentido.

En la película Las invasiones bárbaras, de Denys Arcand, podemos en- contrar un cuadro representativo de este contexto. Rémy es un profesor universitario irremediablemente abatido por el cáncer y próximo a la muerte. Antes de inyectarse una poción letal que lo prive de sus dolores físicos y lo libere del mundo, convoca a sus mejores amigos y con ellos hace un repaso de su existencia:

Hemos sido de todo. Separatistas, independentistas, soberanistas, asociacionistas. Primero fuimos existencialistas. Leíamos a Sartre y Camus. Luego fuimos anticolonialistas como Fanon. Luego leímos a Marcuse y fuimos marxistas. Marxistas-leninistas, trotskistas, maoístas. Luego cambiamos con Soljenitsyne. Fuimos estructuralistas, situacionistas, feministas, deconstruccionistas. ¿Hay algún 'ismo' que no hayamos adorado? Ahora solo somos una manga de cretinistas.

Los antihéroes han leído a Sartre. Para ellos, la vida del hombre no está sujeta a determinismo alguno; el hombre es lo que proyecta ser, "la existencia precede a la esencia" y por tanto no es susceptible de ser explicada en referencia a una naturaleza humana dada. Cada individuo tiene que dar sentido a su vida, a su existencia, y alcanzar este sentido es una constante lucha. Tanto los escritos de Sartre como los de Heidegger (ver su Carta sobre el humanismo, de 1947) y las sucesi-

3 JAMESON, Fredric. Postmodernidad o la lógica cultural del capitalismo tardío, 1991. 
vas respuestas y polémicas promovidas, enfrentan una suerte de desencanto de la modernidad. Se trata de una época en que las respuestas llanas, directas y contundentes ya no son posibles porque no existe un norte a partir del cual estructurarlas, o porque existen muchos nortes que relativizan y revitalizan su entendimiento. Ya no existen las respuestas absolutas, solo flotan las preguntas.

Es la pérdida de la inocencia, la expulsión de la utopía moderna, ante lo cual solo quedan dos caminos: aprender a vivir con el desencanto o construir otra utopía (efímera, digital, de consumo). He aquí la contrarrespuesta a la propuesta adelantada por Husserl en 1935, cuando tenía el pálpito de que las cosas en Europa acabarían muy mal. Si Husserl había propuesto "un heroísmo de la razón",4 tras la guerra la respuesta será un heroísmo del hombre, porque ya vimos que la razón no es de fiar. Como bien señala Birnbaum: "Este desencanto de la modernidad constituye una nueva actitud. Exige un heroísmo distinto, el cual, aunque inspirado en sus formas probadas - heroísmo de la eficiencia, heroísmo de la fuerza moral, heroísmo estético-, está por inventarse aún" ${ }^{5}$
Se trata de vivir la vida humanamente, humanizadoramente, lo que significa huir del "aburrimiento", huida que era para Nietzsche la madre de todas las artes. Por eso, como sugiere Claudio Magris, cada vez más las artes, sensibles tanto a la ambigüedad como a la relatividad de las cosas humanas, abandonan cualquier forma de aspiración a lo absoluto y a la universalidad. ${ }^{6}$ Y si aspiran a ella (a la universalidad) lo hacen desde lo singular, desde la contrariedad y los conflictos que viven los personajes de su universo narrativo.

Frente a la norma y el canon destaca la excepción, el deshecho, lo marginal. Se trata de un tiempo y unos personajes que no entienden la vida como una obra sublime ni pretenden hacer de la existencia un cuadro bellísimo, sino que nos proporcionan historias de vida singulares para ser capaces de contarnos mejor a nosotros mismos quiénes somos. En El desierto rojo, de Michelangelo Antonioni, Mónica Vitti interpreta a Giuliana, una mujer descentrada, desenfocada, inadaptada e inadaptable al mundo. En un momento dado explica su desasosiego insuperable con una frase que, además, revela su única certeza: “Las

4 HUSSERL, Edmund. La crisis de las ciencias europeas y la fenomenología trascendental, 1991, p. 358.

5 BIRNBAUM, Antonia. Nietzsche: Las aventuras del heroísmo, 2004, p. 12.

6 MAGRIS, Claudio. Utopía y desencanto, 2001. 
cosas que me pasan son mi vida". He allí la nueva revelación: al diablo con los dioses, con el Estado, con el psiquiatra, con el Partido, con la economía y con cualquier superchería que aliente la esperanza. Nada de eso. Lo único absoluto es que "las cosas que pasan son la vida" y esa ponderación de lo real, esa resignación a sobrevivirlo que a Giuliana le costaba asimilar, es lo que el antihéroe de esta modernidad en crisis parece haber asumido ya.

Toda esta atmósfera enrarecida en la que se mueve el sujeto, sin embargo, no convierte a los antihéroes en personajes angustiados o en franca desesperación. Por el contrario, parecen aceptar serenamente su destino, como si intuyeran que la vida no necesita tener un sentido para merecer vivirla. Y es que la cultura popular gestada después de la Segunda Guerra parece adscribirse a cierto escepticismo festivo, ligero, en la línea de la ataraxia, y que podríamos explicar a partir del proverbio que reza "El hombre piensa, Dios ríe". La vertiente heroica diría que Dios ríe complacido al ver su obra en actividad. La antiheroica, en cambio, entendería al hombre descocándose por dar con la verdad, mientras Dios ríe porque sabe que la verdad no existe. ${ }^{7}$

Esta impostación, hasta cierto punto, parece sintomática de los días oscuros. Ya en los primeros años del Renacimiento Rabelais había escrito: "Más vale de risas y no de lágrimas que escriba, porque es la risa lo típico del hombre", 8 y de ese modo había asumido el escepticismo festivo, a través del arte como fórmula vicaria para supervivir los tiempos aciagos. Dice Mijaíl Bajtín de los tiempos de Rabelais:

Los problemas arduos y temibles, serios e importantes son transferidos al plano alegre y ligero de los tonos menores. (...) No se trata evidentemente de afirmaciones filosóficas, sino de la dirección tomada por el pensamiento artístico e ideológico, que trata de comprender el mundo desde un punto de vista nuevo, abandonándolo no como un misterio sombrío, sino como un alegre drama satírico. ${ }^{9}$

7 Milan Kundera utiliza este proverbio para explicar las pulsiones que atraviesan el arte de la novela: “iPor qué ríe Dios al observar al hombre que piensa? Porque el hombre piensa y la verdad se le escapa. Porque cuanto más piensan los hombres más lejano está el pensamiento de uno del pensamiento de otros. Y finalmente, porque el hombre nunca es lo que cree ser" (El arte de la novela), 1994, p. 178.

8 Bajtín, Mijaíl. La cultura popular en la Edad Media y el Renacimiento. El contexto de François Rabelais, 1993, p. 209.

9 Ibídem, p. 148. 
La fe en la razón, en la idea de progreso, en la libertad, en el desarrollo de la ciencia y su promesa de una vida mejor para todos, se estrelló contra la mismísima modernidad, y la reacción trajo consigo el desencanto. No en vano la segunda mitad del siglo $X X$ asoma pródiga en antihéroes, todos personajes más asociados al hombre común que al superhombre que debió surgir de esta modernidad que pretendía la utopía de un mundo mejor. Por eso la impostación actual se parece tanto a una gran teoría de la conspiración: es el pensamiento de la sospecha, herencia de Nietzsche, ${ }^{10}$ que reacciona frente a los viejos postulados de la modernidad y está marcado por el descreimiento, por un escepticismo que llevaría a pensar que en verdad Prometeo no quería dar el fuego a los hombres, sino que buscaba hacerse con él de un monopolio internacional.

La antiheroicidad parece haberse impuesto por sobre las grandes fórmulas. No proponemos, ciertamente, que estas sean cualidades únicas de este tiempo, pues los antihéroes, en tanto sujetos ajenos a las glorias y los fastos del modelo de su época, han existido desde que se escriben historias, pero sí sostenemos que la nove- dad del antihéroe moderno estriba en que se ha robado el protagonismo y campea como los mejores héroes de antes.

\section{Antihéroes ribeyrianos: Lo que el tiempo les quitó}

Quizá quien haya narrado con mayor maestría estos tópicos, para el caso peruano, sea Julio Ramón Ribeyro. Sus cuentos son un mosaico personalísimo de la condición humana, esencialmente pesimista, y contienen, desde nuestra perspectiva, los rasgos más saltantes de los antihéroes de la modernidad. Su narrativa breve es un gran patio de ensayo donde los hombres habitan el tiempo más humano de todos, condenados a lo pedestre, lejos de los dioses y de los mitos ancestrales.

La experiencia peruana de la modernidad a la que asistió Ribeyro en la década de 1950 es el telón de fondo de sus cuentos, una modernidad que se abre paso a trompicones y descoordinadamente, un proceso de cambio que encuentra inicuo, superficial, y que le permite ofrecer la visión de una Lima que, al igual que las provincias, "deja de ser una ciudad tranquila y virreinal para reflejar dramáticamente

10 “Guardémonos de los tentáculos de nociones contradictorias como 'razón pura', 'conocimiento absoluto', 'inteligencia absoluta'. Todos esos conceptos sólo guardan detrás la idea de una vida que no es posible imaginar" (NIETZSCHE, Friedrich. La genealogía de la moral, 2004, p. 155). 
las contradicciones sociales y las presiones a las que se ve sometida"11 por los embates de la modernidad; una Lima que antes que curarse de sus largas falencias, ve agudizados todos sus conflictos.

Como señala Adolfo Cisneros, a Julio Ramón Ribeyro el encuentro con su realidad le resulta casi intolerable y el repertorio de cuentos que integran La palabra del mudo refleja una tentativa de representación de la sociedad peruana, en particular de la limeña, a través de personajes, situaciones, temas o símbolos propios de un país latinoamericano en vías de desarrollo y en proceso de mutación. Ribeyro racionaliza y registra los cambios que ocurren como consecuencia de la modernización del Perú, plasmando el cambio social como algo inevitable y conminatorio. ${ }^{12}$

Silvio en el Rosedal y Sólo para fumadores son dos relatos en los que destaca especialmente "el sentido de la vida". En el primero, la búsqueda marca el derrotero, en el segundo, la ausencia de una respuesta se ha integrado perfectamente al derrotero cotidiano.

Empecemos por el primero para desarrollar esta idea. En Silvio en el Ro- sedal el protagonista es un solterón que hereda el Rosedal, una hacienda modelo en el valle de Tarma. Silvio descubre que el rosedal que da nombre al lugar está dispuesto y sembrado conforme a un orden que entiende oculto, místico, cifrado. El jardín se amplifica como una analogía del mundo por descifrar. Silvio ignora su principio y su propósito, lo estudia como queriendo saber las claves de la vida, pero todas las respuestas "lo remitían a la incongruencia", y acaban acentuando la incógnita con respecto a sus días: "Seguía siendo un solterón caduco, que había enterrado temprano una vocación musical y seguía preguntándose para qué demonios había venido al mundo". 13

En cierto momento Silvio cree ver en la organización del jardín las figuras que deletrean la palabra "res" en el alfabeto Morse, pero se ve frustrado cuando procura descifrarla. La acepción latina lo remite a "cosa" y su desconcierto aumenta. "Hizo entonces una lista de lo que le faltaba y se dio cuenta que le faltaba todo". ${ }^{14} \mathrm{La}$ preocupación de Silvio por entender el orden del jardín no es sino la representación del vacío y la rutina en que está sumida su vida. Al pensar el jardín en clave filosófica, Silvio piensa en

11 RIBEYRO, Julio Ramón. La caza sutil (ensayos y artículos de crítica literaria), 1976.

12 CISNEROS, Adolfo. "Alegatos de la modernidad en Julio Ramón Ribeyro". Romance Languages Annual IX, 1998, pp. 444-447.

13 RIBEYRO, Julio Ramón. La palabra del mudo: Cuentos 1952-1993. Volumen III, 1994, p. 130.

14 Ibídem, p. 138. 
la razón de ser de sus días, pues los momentos de mayor interés por el misterio coinciden con sus peores momentos de insatisfacción: "La vida no podía ser esa cosa que se nos imponía y que uno asumía como un arriendo, sin protestar". ${ }^{15}$ Luego descubre que "res" significa "nada" en catalán y concluye que el secreto de la vida es que todo termina en la nada: "Durante varios días vivió secuestrado por esta palabra. Vivía en su interior escrutándola por todos lados, sin encontrar en ella más que lo evidente: la negación del ser, la vacuidad, la ausencia. Triste cosecha para tanto esfuerzo, pues él ya sabía que nada era él, nada el rosedal, nada sus tierras, nada el mundo". 16

Pero, al final, Silvio consigue tranquilidad de espíritu cuando reconoce que, en realidad, la desordenada confusión del jardín no oculta ningún plan secreto:

Silvio trató otra vez de distinguir los viejos signos, pero no veía sino confusión y desorden, un caprichoso arabesco de tintes, líneas y corolas. En ese jardín no había enigma ni misiva, ni en su vida tampoco (...) se sintió sereno, soberano (...) Levantando su violín lo encajó contra su mandíbula y empezó a tocar para nadie, en medio del estruendo. Para nadie. Y tuvo la certeza de que nunca lo había hecho mejor. ${ }^{17}$

De esta manera, Silvio logra reconciliarse con la vida abandonando la vana búsqueda de un significado y aceptando su aparente falta de propósito. Se da cuenta de que la vida no necesita tener un sentido para ser soportable y hasta para proporcionar satisfacción. ${ }^{18}$

La serenidad que alcanza Silvio al final del relato parece ser el puerto de arribo tras un largo viaje existencialista, pues llega a aceptar que jamás será un gran violinista, o un violinista sin audiencia, que su jardín de rosas no guarda ningún misterio y que lo mejor que puede hacer es tomárselo a la buena.

Como si de todas las respuestas que recabó a lo largo de su búsqueda, hubiera decidido quedarse con la del floricultor, cuando Silvio le preguntara por vez primera por el rosedal:

El muchacho le dijo simplemente que él se limitaba a reponer y resembrar las plantas que iban muriendo. Siempre había sido así. Su padre le había enseñado y a su padre su padre. ${ }^{19}$

15 Ibídem, p. 139.

16 Ibídem, pp. 142-143.

17 Ibídem, p. 147.

18 HIGGINS, James. Cambio social y constantes humanas: La narrativa corta de Ribeyro, 1991.

19 Ibídem, p. 140. 
La historia de Silvio es más que otra historia del desencanto, es también el primer capítulo de una postura ante el mundo que se cierra en Sólo para fumadores, donde el protagonista ya no se preocupa por dar con las claves de la vida, sino que dota a sus días de otro sentido, en este caso fumar. El fumador del cuento hace un repaso de sus años a partir de sus cigarros, pero esta premisa se diluye conforme pasan las páginas, pues pronto descubrimos que su vida y sus cigarrillos tienen el mismo peso específico.

El fumar se había ido ya enhebrando con casi todas las ocupaciones de mi vida. Fumaba no sólo cuando preparaba un examen sino cuando veía una película, cuando jugaba al ajedrez, cuando abordaba a una guapa, cuando me paseaba solo por el malecón, cuando tenía un problema, cuando lo resolvía. Mis días estaban así recorridos por un tren de cigarrillos, que iba sucesivamente encendiendo y apagando y que tenían cada cual su propia significación y su propio valor. ${ }^{20}$

El relato se estructura como una sucesión de peripecias que el protagonista debe poner en marcha para surtirse de cigarrillos y mantener activa su cada vez más adictiva afición por fumar. El relato está enfocado y construido desde el consumo de cigarri- llos, pero los datos biográficos del personaje no son datos laterales o secundarios, por el contrario, descubrimos que las acciones de su biografía y su pasión se fundan en el acto mismo de fumar y nada, ninguna otra cosa, llega a ocupar el lugar metafísico que le asigna el narrador.

El personaje es consciente de que fumar se ha convertido en un vicio que incluso le resulta perjudicial, reconoce que su autoestima y dignidad muchas veces se ven melladas a causa de su vocación de fumador, pero jamás se aparta del cigarro, como jamás se plantea la idea de una vida distinta y $\sin$ tabaco. $Y$ es que el cigarrillo es causa y efecto para él, el motor de sus días, el aliciente de su trabajo, el soporte de sus desdichas. Casi se configura como una especie de tótem identitario y vital:

¿Qué me daba el tabaco, entonces, a falta de placeres sensoriales o espirituales? (...) Era el objeto en sí el que me subyugaba, el cigarrillo, su forma tanto como su contenido, su manipulación, su inserción en la red de mis gestos, ocupaciones y costumbres cotidianas (...) Como todo hábito se había agregado a mi naturaleza hasta formar parte de ella, de modo que quitármelo equivalía a una mutilación (...) me procuraba un sentimiento de calma y de bienestar difuso. ${ }^{21}$

20 RIBEYRO, Julio Ramón. La palabra del mudo, volumen IV, p. 18.

21 Ibídem, p. 36. 
El cigarrillo es la pregunta y la respuesta que persigue Silvio. Desprovistos de los aparatos generadores de sentido, solo queda reinventarse y refundarse a partir de nuevos mitos, ya no instaurados sobre la base de un colectivo, sino a partir de uno mismo. El escepticismo lo ha teñido todo; si la utopía se marchitó, si el futuro es ahora, el antihéroe se articula a partir del descompromiso gregario, superviviendo el presente como la utopía que está realizándose.

\section{Bibliografía}

BAJTÍN, Mijaíl. La cultura popular en la Edad Media y en el Renacimiento. El contexto de François Rabelais. México: Alianza Universidad, 1993.

BIRNBAUM, Antonia. Nietzsche: Las aventuras del heroísmo. México: Fondo de Cultura Económica, 2004.

CISNEROS, Adolfo. "Alegatos de la modernidad en Julio Ramón Ribeyro". Romance Languages Annual IX, 1998.

HIGGINS, James. Cambio social y constantes humanas: La narrativa corta de Ribeyro. Lima: Pontificia Universidad Católica del Perú, 1991.
HUSSERL, Edmund. La crisis de las ciencias europeas y la fenomenología trascendental. Barcelona: Crítica, 1991.

JAMESON, Fredric. Postmodernidad o la lógica cultural del capitalismo tardío. México: Siglo XXI, 1991.

KUNDERA, Milan. El arte de la novela. Barcelona: Tusquets, 1994.

MAGRIS, Claudio. Utopía y desencanto. Barcelona: Anagrama, 2001.

NIETZSCHE, Friedrich. La genealogía de la moral. Madrid: Alianza Editorial, 2004.

RIBEYRO, Julio Ramón. La palabra del mudo: Cuentos 1952-1993. Volúmenes III y IV. Lima: Jaime Campodónico, 1994.

—. La caza sutil (ensayos y artículos de crítica literaria). Lima: Milla Batres, 1976.

WOLF, Janet. La producción social del arte. Madrid: Istmo, 1997.

\section{Filmografía referencial}

Il deserto rosso. Director: Michelangelo Antonioni. 1964. Cinematografica Federix, Film Duemila, Lux.

Les invasions barbares. Director: Denys Arcand. 2003. Astral Films y Canal+. 